been confirmed by synthesis. Since both our unpublished studies and Ungar (1970a) showed, with crude preparations, that there is no crossover effect between dark and step-down avoidance, an effect due to the conditioning stimulus is ruled out and specificity of the active molecule is clearly seen. Further distinction between the two molecules is emphasized by the sensitivity of scotophobin to trypsin, but not to chymotrypsin (Ungar, 1970b), and the sensitivity of crude preparations of step-down avoidance principle to both proteolytic enzymes. We propose the name "catabathmophobin" for the active step-down avoidance principle (from the Greek kata = down, bathmos = step, and phobos = fear).

It is, therefore, becoming increasingly clear that there is a family of relatively small peptides, in the $\mathrm{MW}$ 1,500 range, which are active in passive transfer of rather simple behavioral responses. Our current work, aimed at the complete structural identification of the step-down avoidance peptide, should help determine the general structural qualifications for transfer activity as well as for specificity in much the same way that immunoglobulins are now known to require a general structure which allows reaction with antibody as well as specific amino acid sequences in the variable portion of the immunoglobulin which controls specificity of the response.

An analogy also exists between the present status of our knowledge of the molecular identification of the first passive transfer molecule, scotophobin, and the state of enzymology in 1926, when Sumner crystallized the first enzyme, urease, and showed that it was a protein. Enzymologists of the 1930 s argued furiously about whether or not enzymes were proteins, and some were not convinced until several other enzymes were crystallized and shown to be proteins. An added problem in the clarification of passive transfer of learned behavior which did not exist in early enzymology is that behaviorai and biochemical conditions required for even the demonstration of passive transfer of learned behavior are so poorly known that we have almost simultaneous reports of failure to demonstrate any passive transfer (Lepore et al, 1970) from one laboratory and structural resolution of passive transfer molecule from another (Ungar et al, 1971).

REFERENCES

BYRNF, W. L. (Ed.) Mntrewtar approaches to tcoming and memory. New Yurk: Academic Press, 1970.
KATZ,M.S.\& HALSTEAD, W. C. Protein organiration and mental function. Comparative Psychology Monograph. $1950,20(1), 1-38$

LEPORE, F. DUCHARME, R., \& CARDU. B. Memory and ribonucleic acid (RNA): Transfer of an avoidance responst. Psychological Reports, 1970,27,99-103. UNGAR. G. (Ed.) Molecular mechanisms in memory and learning. New York: PJenum, 1970a. Pp. 149-175.
UNGAR, G. C'bemical tranifor of leamed information. in W. [. Byrne (Ed.). Molecular approache's (o learning and memory. New York: Academic Press, 1970b. Pp. 179-187.

NOTE

1. Ungar. G., Desiderio. D. M., and Parr, W. Isolation, identification and synthesis of a specific-behavior-inducing brain peptide. Submitted for publication.

\title{
The incubation effect produced in rats without footshock*
}

\author{
JOHN P. J. PINEL† \\ University of British Columbia, Vancouver, Canada \\ and \\ CHARLES W. MALSBURY and MICHAEL EDWARD CORCORAN \\ McGill University, Montreal, Canada
}

A noncontingent aversive treatment consisting of high-intensity sound and air blast was administered to rats in an open field. These animals were returned to the open field $30 \mathrm{sec}, 1 \mathrm{~min}, 10 \mathrm{~min}, 1 \mathrm{~h}, 3 \mathrm{~h}$, or $8 \mathrm{~h}$ later, and their activity levels were recorded. The aversive treatment significantly reduced activity from pretreatment levels. The magnitude of this reduction increased with increases in the treatment-test interval. Thus, it was clearly shown that the "incubation effect" is not peculiar to situations in which footshock serves as the noxious stimulus.

After a noncontingent footshock (FS) administered in an open field, the freezing behavior observed during reexposure to that open field increases with increases in the duration of the FS test interval (Pinel, 1970). In a recent paper, Pinel, Corcoran, and Malsbury ${ }^{1}$ showed that this increase in freezing after FS is not attributable to an increase in the tendency to freeze, but rather is related to the transient activating effects of FS. Animals tested soon after FS were relatively active, not because there was little tendency to freeze at that time, but because the freezing effects were being partially counteracted by FS-produced activation. The increases in freezing seen with increases in the duration of the FS test interval reflected a diminution of these activating effects. Thus, it appears that the failure to freeze in the intervals after FS was not merely a passive deficit due to the slowness of mechanisms underlying the development of FS-produced freezing. There seem to be mechanisms which actively delayed the onset of

* Supported by Canadian National Research Council Grant APA-66 awarded to $P$. M. Milner. The senior author was supported during preparation of the manuscript by National Institute of Mental Health Grant 5-R01-MH07923 awarded to S. L. Chorover.

tRequests for reprints should be sent to John Pine?. who is now at the Department of Psychology. University of Britisti Columbia, Vancouver 8 , Canada. freezing and thus ensured that animals remained active in the immediate post-FS period.

These mechanisms seem to underlie a number of different phenomena which all have been included under the label of "incubation effect." In the one-trial passive avoidance and conditioned emotional-response situations, where increases in freezing can result in improved performance, performance has been shown to improve with increases in the duration of the FS test interval (McGaugh, 1966; Pinel \& Cooper, 1966; Tarpy, 1966). On the other hand, in the one-trial active avoidance situation, increases in freezing disrupt avoidance and performance has been found to deteriorate as the duration of the FS test interval increases (Pinel, 1968).

Numerous investigators have demonstrated the incubation effect in a wide variety of species and under a wide variety of conditions (e.g., Bovet, Filomena, \& Alberto, 1969; McMichael, 1966; Zammit-Montebello, Black, Marquis, \& Suboski, 1969). This suggests that the incubation effect might reflect a natural behavior pattern which may have survival value for a number of different species. This conjecture, however, remains in doubt because FS has been used as the aversive stimulus in all demonstrations of the incubation ef fect. On the basis of existing data, it is hard to rule out the possibility that the incubation effect 


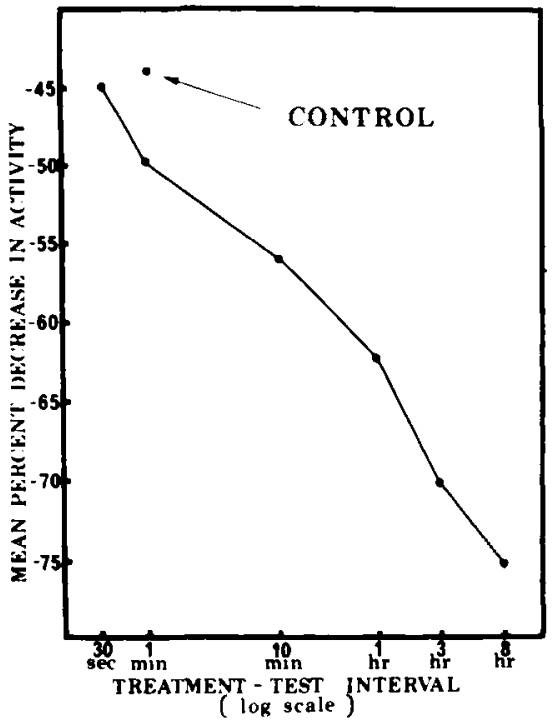

Fig. 1. The reduction of activity produced in rats at various intervals after a combination of air blast and high-intensity sound.

just reflects a peculiar response to FS which has no relation to an animal's behavior in its natural environment. The purpose of the present experiment was to demonstrate that the incubation effect in rats is not specific to FS. The aversive stimulus employed was a combination of two stimuli which have previously been shown to be aversive to the rat: high-intensity sound (Barnes \& Kish, 1957; Campbell \& Bloom, 1965) and air blast (Ray, $1966 \mathrm{a}, \mathrm{b}$ ).

\section{SUBJECTS}

The Ss were 80 naive male 200 - to $250 . \mathrm{g}$ black-hooded rats purchased from the Quebec Breeding Farm. The animals were housed in groups of three throughout the experiment and were given continuous access to food and water in their home cages.

APPARATUS

The testing apparatus consisted of a $44 \times 44 \times 44 \mathrm{~cm}$ box. The floor of the apparatus was divided into nine equal squares for measuring activity. The tone was delivered through a speaker mounted on the apparatus. The high-intensity sound, as measured from the floor of the apparatus, was about $110 \mathrm{~dB}$ at $4,000 \mathrm{~Hz}$. The air blast was delivered through flexible plastic tubing, hand-held and directed at the head of the animal.

PROCEDURE

Individual Ss were placed in the open field, and their preshock activity, as defined by the number of squares entered in $3 \mathrm{~min}$, was recorded. The three rats whose activity scores were below 20 entries in $3 \mathrm{~min}$ were dropped from the experiment. The 77 animals which met the criterion were randomly divided into seven groups.
On the day following preshock screening, the rats in the six experimental groups received the noncontingent air-blast/sound treatment. This consisted of three 5 -sec presentations of air blast and high-intensity sound, separated by 10 -sec intervals. Immediately after treatment, each rat was removed from the apparatus and returned to its home cage. Ss in these six experimental groups were returned to the apparatus for a $3-\mathrm{min}$ activity test $30 \mathrm{sec}, 1 \mathrm{~min}$, $10 \mathrm{~min}, 1 \mathrm{~h}, 3 \mathrm{~h}$, or $8 \mathrm{~h}$ later. Ss in the control group were placed in the apparatus for $40 \mathrm{sec}$ but did not receive the aversive stimulation. After the $40 \mathrm{sec}$, each control animal was placed in its home cage for $1 \mathrm{~min}$ before being returned to the open field for testing. All seven groups consisted of 10 rats, except for the 30-sec experimental group, which consisted of 17.

\section{RESULTS AND DISCUSSION}

The raw activity scores for each animal were transformed to percent change scores for the purpose of analysis. This was done by subtracting the posttreatment activity score from the pretreatment activity score and multiplying by 100 . These data are summarized in Fig. 1 . It is readily apparent from Fig. 1 that the tone and air-blast treatment produced a significant decrease in activity in all of the experimental groups (all sign test ps $<.05$ ). Only 2 of the 67 experimental animals were more active after treatment than before.

The data analysis indicated that the magnitude of the treatment-produced reduction of activity increased with increases in the treatment-test interval. Significant differences were found between the transformed scores of the 30 -sec group and the $1 \cdot, 3-$, and $8 \cdot h$ groups and between the 1 -min group and the 8 -h group (all Mann-Whitney ps $<.05$ ).

In this experiment the control group also showed a significant decrease in activity (sign test $\mathrm{p}<.05$ ). This is not surprising since the rats in this group had an opportunity to explore the open field undisturbed for $40 \mathrm{sec}$ just $1 \mathrm{~min}$ prior to being tested. The experimental groups, on the other hand, did not have the opportunity to explore while they were receiving the treatment. Thus it is not clear what value, if any, there is in making direct comparisons between the experimental groups and the control group. In previous experiments in which we used FS as the aversive stimulus, control animals were typically placed in the open field for only $5 \mathrm{sec}$ and no such diminution of activity resulted. In any case, in the present experiment, the decrease in activity produced at long intervals by the air-blast/sound treatment was much greater than that seen in the control animals.

The present experiment indicates that the incubation effect may be a general response to a wide range of noxious stimuli rather than a specific response to FS. Conceivably, any of a wide range of noxious stimuli that evoke freezing behavior will result in an incubation effect. In other words, when a stimulus is aversive enough to induce freezing, there seem to be mechanisms which ensure that the animal remains temporarily active. When a traumatic event occurs to an animal in its natural environment, it invariably requires immediate action on the part of that animal in the form of an attack, an escape, or, in some cases, an investigatory response (Hudson, 1950). It is, thus, clearly important that freezing tendencies not be allowed to interfere with these coping responses. In this light, the evolutionary value of a mechanism that delays the onset of trauma-induced freezing is readily apparent.

\section{REFERENCES}

BARNES, G. W., \& KISH, G. B. Reinforcing properties of the termination of intense auditory stimulation. Joumal of Comparative \& Physiological Psychology. $1957,50,40-43$.

BOVET, D.. FILOMENA, B.. \& ALBERTO. $O$. Genetic aspects of learning and memory in mice. Science, $1969,163$. 139-149.

CAMPBELL, B. A., \& BLOOM, J. $M$. Relative aversiveness of noise and shock. Journal of Comparative \& Physio gical Psychology, 1965, 60, 440-442.

HUDSON, B. B. One trial learning is the domestic rat. Genetic Psychology Monographs, 1950, 41, 99-145.

McGAUGH, J. L. Time-dependent processes in memory storage. Science, 1966, 153. $1351 \cdot 1358$.

McMICHAEL, J. S. Incubation of anxiety and instrumental behavior. Journal of Comparative \& Physiological Psychology. $1966,61,208-211$.

PINEL, J. P. J. An evaluation of the one-trial avoidance task as a tool for studying memory. Psychonomic Science. $1968,13,134-135$.

PINEL, J. P. J. Two types of ECS-produced disruption of one-trial training. Joumal of Comparative \& Physiological Psychology, 1970,72,272-277.

PINEL, J $P$ J \& COOPER, $R$. M. The relationship between incubation and ECS gradient effects. Psychonomic Science, $1966,6,125-126$.

RAY, A. J. Shuttle avoidance: Rapid acquisition by rats to a pressurized air unconditioned stimulus. Psychonomic Science, 1966a, 5, 29-30.

R A Y, A. J. Non-incremental shuttle-avoidance acquisition to pressurized air US. Psychonomic Science. $1966 b, 5,433-434$.

TARPY, R. M. Incubation of anxiety as measured by response suppression. Psychonomic Science, 1966, 4, 189-190.

ZAMMIT-MONTEBELLO,A., BLACK, M., MARQUIS, H. A., \& SUBOSKI, M. D. Incubation of passive avoidance in rats: Shock intensity and pretraining. Journal of Comparative \& Physiological Psychology, 1969, 69, 579-582. NOTE

1. Manuscript in preparation. 